\title{
EFFECT OF AMOUNT OF DEFORMATION ON MICROSTRUCTURE Evolution During CONTROLled COOLING OF Forgings FROM FINISH-FORGING TEMPERATURE
}

\author{
Jana Čubrová, Ivan Vorel, Filip Vančura, Bohuslav Mašek \\ University of West Bohemia, Univerzitni 22, 30614 Plzeň, Czech Republic
}

\begin{abstract}
The present paper deals with the effect of the amount of deformation introduced during closed-die forging of parts from 30MnVS6 microalloyed steel upon the final microstructure after controlled cooling. As various locations within forged parts experience various accumulated strains, it is not straightforward to estimate the prior recrystallization-controlled microstructural evolution in such locations during cooling from the finish-forging temperature. Material-technological modelling offers an efficient way of dealing with such problems [1]. It uses a small amount of material (a model) and a processing schedule which is identical to the schedule, used with a real-life forging. The simulator applies an exact sequence of deformation and thermal processing steps to the tested sample. As the model is made of the actual material, it can also be used for mechanical testing and microstructure characterization. Therefore, the final properties of forged parts can be documented or predicted with high accuracy without interfering with the manufacturing process [2].
\end{abstract}

Keywords recrystallization; 30MnVS6 ; Controlled Cooling; Real forging; The degree of deformation
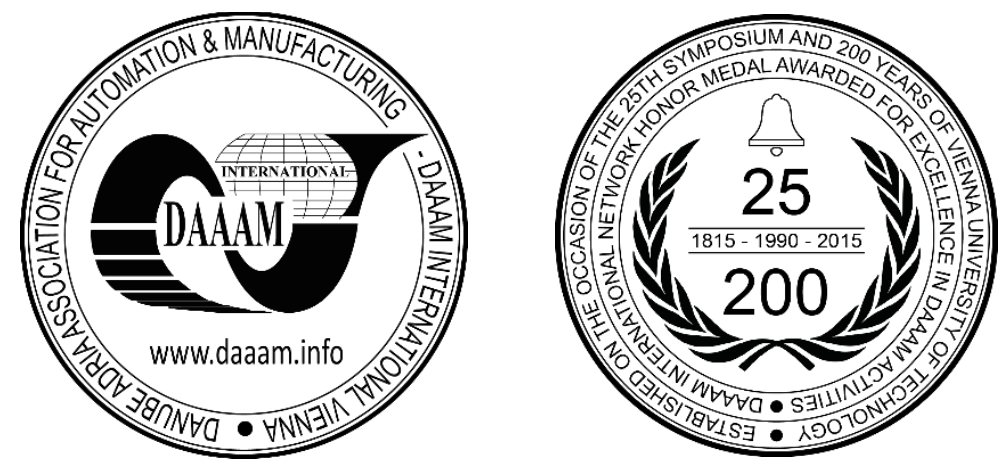

This Publication has to be referred as: Cubrova, J[ana]; Vorel, I[van]; Vancura, F[ilip] \& Masek, B[ohuslav] (2016). Effect of Amount of deformation on Microstructure Evolution During Controlled Cooling of Forgings from FinishForging Temperature, Proceedings of the 26th DAAAM International Symposium, pp.0892-0896, B. Katalinic (Ed.), Published by DAAAM International, ISBN 978-3-902734-07-5, ISSN 1726-9679, Vienna, Austria

DOI: $10.2507 / 26$ th.daaam.proceedings. 124 


\section{Introduction}

Metals respond to plastic deformation by strain hardening. From the thermodynamic viewpoint, the strainhardened condition is characterised by thermodynamic non-equilibrium. When steel undergoes plastic deformation, its internal energy increases because of the growing number lattice defects. The structure of the steel thus becomes metastable. During hot working, thermodynamic equilibrium is achieved through dynamic recrystallization which reduces entropy and the number of lattice defects. The driving force for these processes depends on how far from equilibrium the internal state of the steel has become due to forming. The extent and rate of dynamic recrystallization depend on the amount and rate of deformation and on temperature, at which it takes place. The progress of dynamic recrystallization which accompanies hot forming and the extent of the post-forge recrystallization affects the microstructural evolution during subsequent cooling of the forged parts. This applies, in particular, to its grain size and phase composition.

The significant interrelationship of hardening and softening process is found in microalloyed steels for forging as well. Their resulting microstructure depend on strain and recrystallization-related phenomena, as well as on the method and rate of cooling upon forging. Thanks to material-technological modelling it is easier to control the whole process for these steels as well. Using material-technological modelling, the real life closed -die forging process is tested on a specimen mounted in a thermomechanical simulator which substitutes the actual forming sequence with a tensioncompression schedule.

\section{Experimental programme}

The objective of this experimental programme was to clarify the impact of the total logarithmic strain and subsequent recrystallization upon microstructure evolution at selected points within a real-life forged part during controlled cooling from a fixed finished-forging temperature. In this experiment, the boundary condition was achieving ferrite-pearlite microstructure in microalloyed steel 30MnVS6 for forging. The experiment was carried out on a demonstration forging used as a part of a truck running gear (Fig. 1).
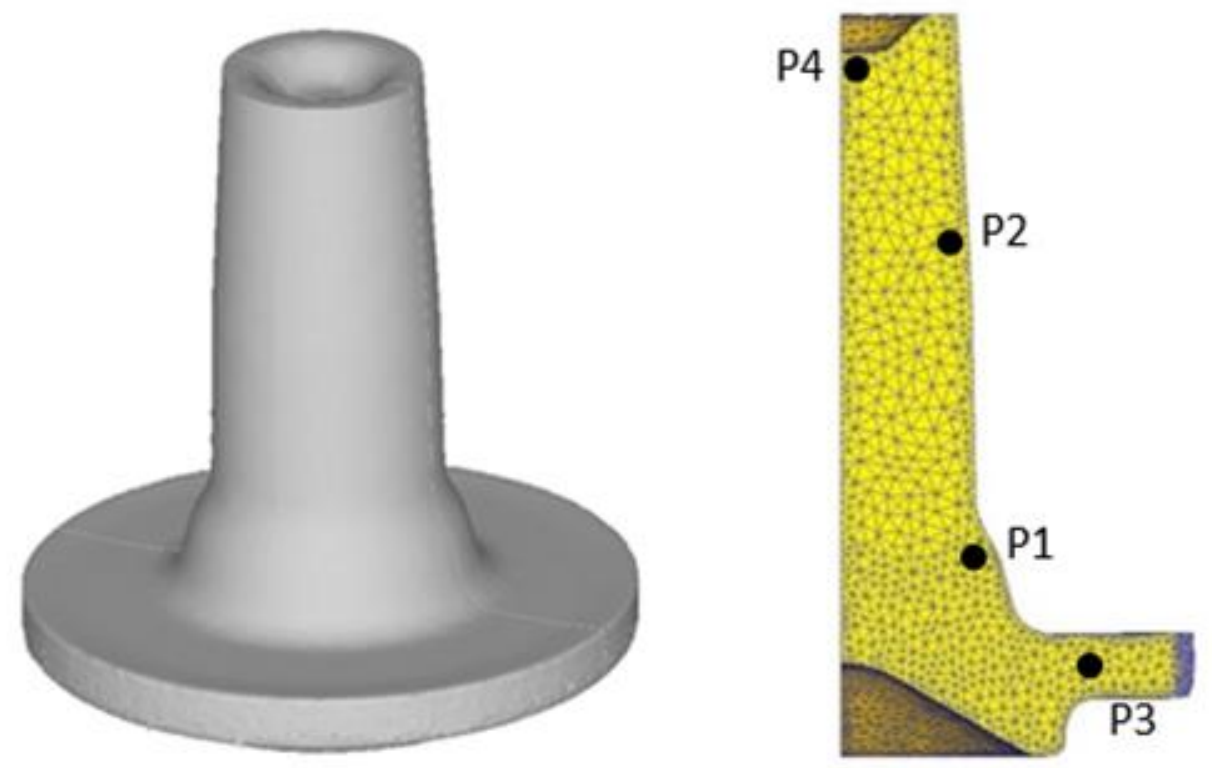

Fig. 1. Forged part with marked areas in which local microstructure development was tracked

The part is forged between 1235 and $1150{ }^{\circ} \mathrm{C}$ using four progressive operations: upsetting, blocking, finishing and shearing. The FEM computation uses measured data from the real-world operation: times, temperatures, forming machine characteristics and mechanical and thermophysical properties of the material being forged. Such data is measured in order to construct an accurate material-technological model which can describe the real-life behaviour of the material being formed and heat-treated. It accounts for the relations between flow stress levels and strain magnitudes, strain rates and temperatures. The results of the FEM simulations include temperature-time and strain-time profiles in specific locations on the part's cross-section. Therefore, the key task in material-technological modelling is the conversion of the real-life logarithmic strain as found by the FEM simulation to the thermomechanical simulator crosshead movement.

Based on data from FEM simulations, important points were identified on the forging's cross-section. At these points, true strain levels were determined by calculations: the lowest $(\varphi=0.6)$, medium $(\varphi=1.8),(\varphi=3.5)$, and the highest level ( $\varphi=5.5)$ (Fig. 2) [4]. 


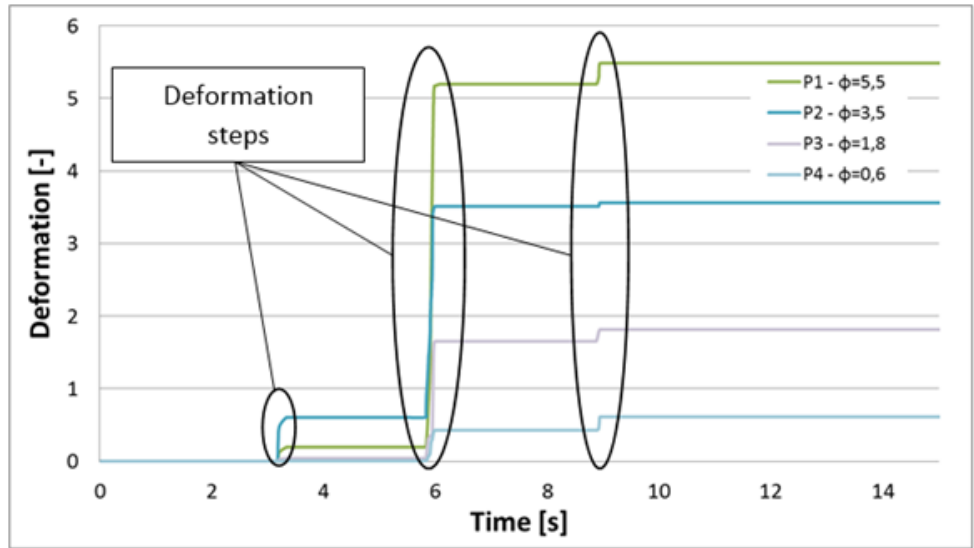

Fig. 2. True strains at monitored points on forging's cross-section

For these points, material-technological models were constructed, verified and optimised [5, 6, 7]. Based on previous research, the temperature curve for the controlled cooling simulation was proposed to provide ferrite-pearlite microstructure throughout the volume of the forged part (Fig. 3) [7, 8].

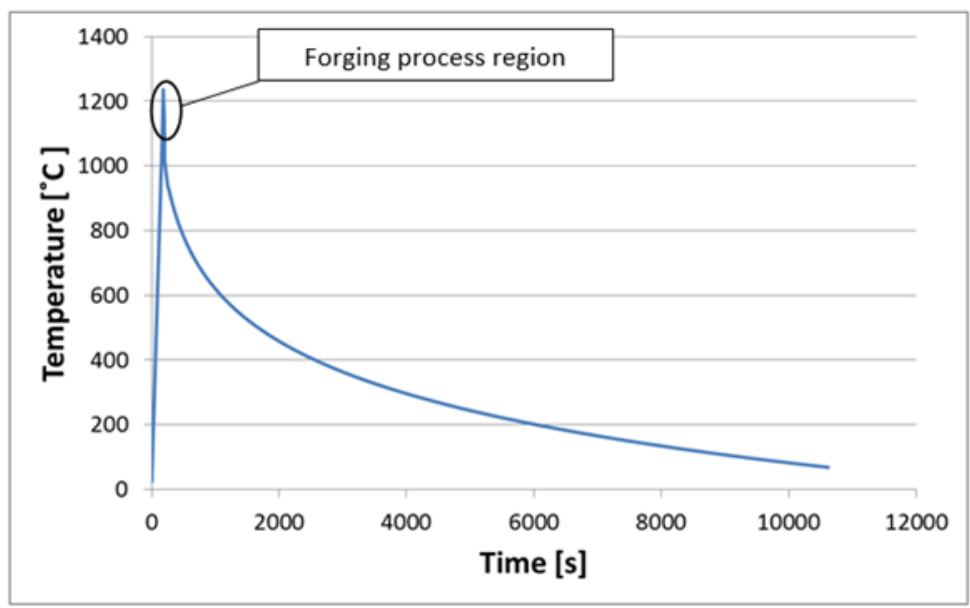

Fig. 3. Controlled cooling curve which leads to ferrite-pearlite microstructure

\section{Results and discussion}

The effect of the amount of logarithmic strain on the evolution of microstructure of 30MnVS6 steel for forging revealed considerable differences (Fig. 4, 5). In all material-technological models, the required ferrite-pearlite microstructure was obtained. Their comparison showed that the size of both ferrite and pearlite particles decreases with increasing true strain (Fig. 4, 5).
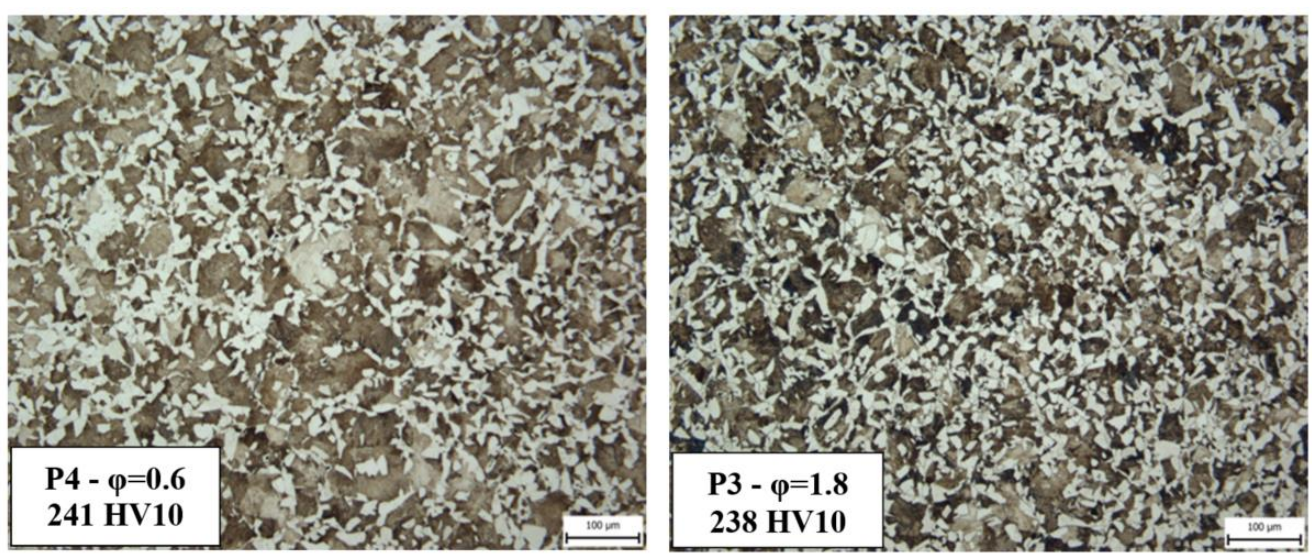

Fig. 4. Microstructures at points P4 and P3 upon controlled cooling which followed after forging between 1235 and $1150{ }^{\circ} \mathrm{C}$ 

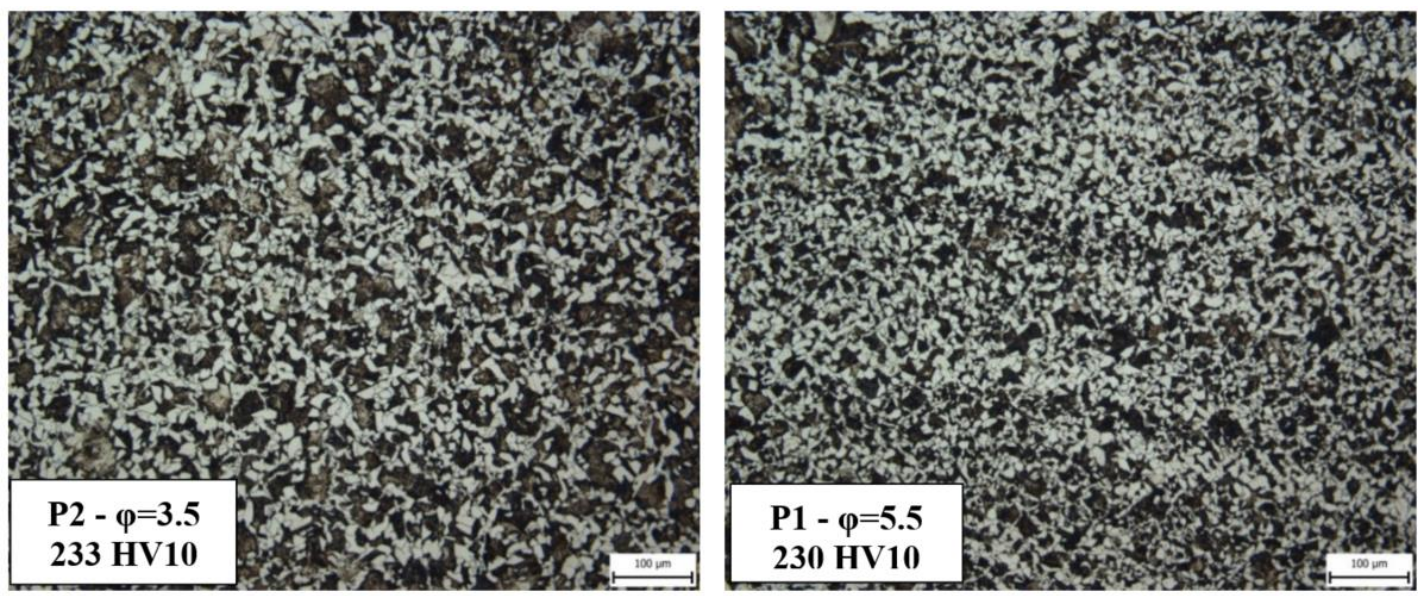

Fig. 5. Microstructures at points P2 and P1 upon controlled cooling which followed after forging between 1235 and $1150{ }^{\circ} \mathrm{C}$

The total true strain level also affected the proportions of ferrite and pearlite. In individual models, an increase in strain led to an increase in the ferrite fraction and to a decrease in the pearlite fraction. In the model which experienced the lowest true strain, the final hardness was $241 \mathrm{HV} 10$. In the other models, hardness levels were lower. The lowest hardness was found in the model with the highest true strain: $230 \mathrm{HV} 10$. Considering the dynamic recrystallization which took place in the models, one can conclude that the higher the true strain at a given forging temperature, the smaller is the grain size in the resulting ferrite-pearlite microstructure. By contrast, lower strain levels make recrystallization easier, leading to coarser microstructures.

\section{Conclusions}

Material-technological modelling was employed to clarify the effect of the amount of true strain and subsequent dynamic recrystallization on microstructure development during controlled cooling from the finish-forging temperature in a demonstration forged product. Using data obtained from FEM simulations, significant locations within a real-life forging were identified, which experienced the lowest, medium and the highest total true strains. Material-technological models were constructed for these points to simulate the forming process and the subsequent controlled cooling of the real-life forging of microalloyed steel.

The purpose of these models was to obtain information on the effect of true strain and dynamic recrystallization upon microstructure evolution. A fixed range of forging temperatures was used. The results of the experiment confirmed the assumption that the microstructure becomes finer with increasing amount of deformation. The fraction of ferrite increases, whereas that of pearlite decreases. In addition, it was found that an increase in the total strain leads to lower hardness. Considering dynamic recrystallization, one can conclude that at a given temperature and lower strain amounts, dynamic recrystallization proceeds more easily. The present results obtained by means of material-technological modelling highlight the variation in the development of the morphology of ferrite-pearlite microstructure at various points within a demonstration forged product. This may lead to variation in mechanical properties. As the material-technological models used in the present investigation permit both microstructure characterization and mechanical testing, this variation can be documented effectively [8]. That will be another stage of this research. The resulting information may be used for developing and optimizing new manufacturing routes for making forged parts.

\section{Acknowledgements}

This paper includes results created within the projects LO1412 Development of West-Bohemian Centre of Materials and Metallurgy and SGS-2013-028 Support of Students' Scientific Activities in the Area of Material Engineering. The projects are subsidised by the Ministry of Education, Youth and Sports from specific resources of the state budget for research and development.

\section{References}

[1] B. Mašek, H. Jirková, J. Malina, L. Skálová, L. W. Meyer, Physical Modelling of Microstructure Development During Technological Processes with Intensive Incremental Deformation., Key Engineering Materials, 2007 , Vol. 345-346, No. 1-2, pp. 934-946, ISSN 1013-9826.

[2] B. Mašek, H. Jirková, L. Kučerová, A. Ronešová, J. Malina, Material-Technological Modelling of Real Thin Sheet Rolling Process., METAL 2011., 20th Anniversary International Conference on Metallurgy and Materials, 2011, pp. 216-220. Edit. TANGER Ltd., ASM Int, Mat Informat Soc; CSNMT; VSB-TU. ISBN 978-80-87294-24-6. 
[3] Zhang Tong - Bo et al., New Type Austenitic Dynamic Recrystallization of Microalloyed Forging Steels 38MnVS6 During Forging Process., Journal of Iron and Steel Research, 2013, 20(5):57-60, ISSN 1006-706X.

[4] M. Fedorko, L. Maleček, Construction of Numerical Model of Forging Process of Four-pole Rotor Shaft., Hutnické listy, 2012, Vol. LXV, No. 4, ISSN 0018-8069.

[5] V. Pileček, F. Vančura, H. Jirková, B. Mašek, Material-Technological Modelling of Die Forging of $42 \mathrm{CrMoS4}$ Steel., Materiali in technologije, 2014, Vol. 48, Issue 6, pp. 869-873, ISSN 1580-2949.

[6] I. Vorel, V. Pileček, F. Vančura, H. Jirková, B. Mašek, Material-Technological Modelling of C45 Steel Die Forgings., Procedia Engineering. (DAAAM 2014), 2015, Vol. 100, Issue C, pp. 714-721, ISSN 1876-6102.

[7] F. Vančura, I. Vorel, V. Pileček, B. Mašek, Material Technological Modelling of Thermomechanical Processing of Die Forging of Microalloyed Steel., Kovárenství, 2015, ISSN 1213-9289.

[8] B. Mašek, H. Jirková, J.Malina, D. Klauberová, The Material-Technological Modelling of the Real Dynamic Process, Procedia Engineering. (DAAAM 2010), 2010, Vol. 21, No.1, ISSN 1726-9679. 